\title{
Reconceptualising Learning and Teaching staff development at Strathclyde: supplementing formal provision with informal spaces
}

\author{
Sean Morrissey \\ University of Strathclyde, UK \\ Katy Savage \\ University of Strathclyde, UK
}

Keywords: Covid-19; academic development; professional identity; blended learning; online learning; peer support for staff.

\section{The challenge}

The sector-wide pivot to blended/online learning in response to the Covid-19 pandemic brought with it innumerable challenges and opportunities. As members of an Educational Development team at the University of Strathclyde - a research intensive university - we were tasked with supporting staff throughout the institution to respond quickly to these challenges and embrace the opportunities of blended/online learning.

Across the sector, new directions in professional educational development often draw influence from the work of Lave and Wenger (1991) in focussing on the informal, situated aspects of professional development. This can include 'opportunities [...] for informal discussions and shared work' (e.g., Trowler and Knight, 2000) and activities like mentoring (e.g., Boeren et al., 2015), 'professional dialogues' (e.g., Feiman-Nemser, 2001), and practice sharing. Where technology is concerned however, Vaughan and Garrison's (2006) suggestion, that professional development for online learning tends to focus on operational capabilities rather than digital literacies for educators (e.g., Higher Education Academy, 2017), remains a poignant one.

Drawing on insights from the literature, we recognised that our response at Strathclyde did, indeed, need to address key operational competencies. Developing an online 
programme requires a different set of staff skills, compared with face-to-face delivery (Hixon et al., 2018). Lu, Todd and Miller have described the digitalisation of teaching as a 'paradigm shift', akin to 'learning a new language' (Lu, Todd and Miller, 2011). Our questions in this regard included: how to help teaching staff acquire the knowledge and capabilities required to develop high quality, evidence-informed, flexible student experiences, and how to leverage the experience of 'early adopters' and disseminate good practice.

Yet, from an 'affective' perspective, the literature indicated that the implementation of new technologies in teaching can also precipitate a loss of control, which can lead to paralysis and disrupt the 'professional identities' of staff (Alvarez, 2008). Many colleagues faced additional pressures during the first wave of the pandemic, including (but by no means restricted to), work-life balance, job-security, health concerns, and so on. In the educational development team, we cared deeply about this because we were experiencing many of these challenges first-hand.

We had many years' experience of offering flexible development opportunities at Strathclyde, with peer-support networks (e.g. Savage et al., 2021) being a particular area of focus. However, the impact of the pandemic on staff in an affective sense motivated us to develop a rich and diverse programme of support and development that included formal training and CPD opportunities - informal spaces for peer support and mechanisms for sharing good practice and disseminating experiences.

\section{The response}

From March 2020, the academic development team at Strathclyde initiated a programme of workshops on blended/online learning design for programme leaders across the university. Recognising that we, ourselves, were programme leaders, we 'put our money where our mouth was' and redesigned the modules on our PGCert to accommodate fully online study.

We also worked with a team of 'early adopters' to create self-paced online CPD opportunities on topics such as flipped classes, learner agreements, and engaging audiences online. 
We also initiated a mailing list, for staff to pose questions, highlight experiences, and offer mutual support, and a blog. The blog quickly became an opportunity for staff to reflect more deeply on their experiences of technology-enhanced learning and to share good practice with others.

These formal activities were supplemented by drop-in sessions and a 'teachers' lounge' to promote staff well-being. Our participation in an Advance HE Good Practice Grant (Savage et al., 2021) project during this period also led to the reinvigoration of a number of peer support networks that had been dormant.

The teachers' lounge was regularly attended by a member of staff who had joined the university immediately after the closure of campus. This provided a valuable place for that member of staff to ask questions, meet colleagues, and feel a sense of belonging in a group of likeminded peers. Similarly, the drop-in sessions functioned as spaces for professional dialogue amongst teaching staff. Often participants would bring challenges to the sessions, which ranged in scope from the development of online teaching activities to the use of virtual learning environments to deliver assessment and feedback. These problems were then worked through collectively, leading to the provision of novel solutions, reflection on action, and practice sharing.

\section{Recommendations}

Between March and July 2020, we tracked around 1400 direct engagements across all of these resources. While the impact of informal provision can be notoriously difficult to quantify, our evaluation of these activities pointed to a number of tangible benefits. By supporting staff in developing specific skills in digital education, our colleagues told us that their motivation and enthusiasm for teaching online increased. A survey of peer-support network participants during the first wave of the Covid-19 pandemic also found that around $60 \%$ of participants made changes to their teaching as a direct result of their participation in one or more network(s). New relationships with colleagues and a sense of belonging similarly emerged as key outcomes of this diverse staff development programme. 
The informal activities, in particular, provided valuable opportunities for the educational development team to keep a finger on the pulse of staff and evolve the programme accordingly. By early 2021, for example, in response to growing concerns about staff wellbeing, we decided to implement a new programme of CPD activities called 'Keeping Well, Teaching Well'. Similarly, a weekly programme of micro-CPD was initiated earlier this year due to the admission of many colleagues in these informal spaces that they were 'beginning to neglect their own professional development'.

Clearly, the overwhelmingly positive response to our new programme of staff development activities was, in part, due to a surge of enthusiasm from teaching staff across the university, not to mention the necessity of learning new skills to pivot online. However, the number of engagements from staff remains high vis-à-vis the months and years pre-Covid19. By offering them a responsive and differentiated programme, staff involved in learning and teaching at Strathclyde seem to have to have appreciated an approach that respects their individual needs and the diversity of our staff community.

In conclusion, the education development team at Strathclyde recommends the benefits of a dynamic blend of formal and informal spaces for professional development. In particular, drop-in sessions, peer support networks, and coffee lounges were particularly impactful for staff during the first wave of the pandemic. These spaces supported the well-being and resilience of teaching staff, promoted learning and development, and fostered the building of meaningful, collaborative relationships in the face of uncertainty and change. $A$ programme comprised of these elements offers a sustainable way forward for academic development.

\section{References}

Alvarez, R. (2008) 'Examining technology, structure and identity during an Enterprise System implementation', Information Systems Journal, 18(2), pp.203-224.

Boeren, E., Lokhtina-Antoniou, I., Sakurai, Y., Herman, C. and McAlpine, L. (2015) 'Mentoring: a review of early career researcher studies', Frontline Learning Research, 3(3), pp.68-80. https://doi.org/10.14786/flr.v3i3.186. 
Feiman-Nemser, Sharon (2001) 'Helping novices learn to teach: lessons from an exemplary support teacher', Journal of Teacher Education, 52(1), pp.17-30. https://doi.org/10.1177/0022487101052001003.

Higher Education Academy (2017) Digital Literacies. Available at: https://www.heacademy.ac.uk/knowledge-hub/digital-literacies (Accessed: 1 April 2021).

Hixon, E, Barczyk, C., Buckenmeyer, J. and Feldman, L. (2018) 'Mentoring university faculty to become high quality online educators: a program evaluation', Online Journal of Distance Learning Administration, 14(5), pp.2011.

Lave, J. and Wenger, E. (1991) Learning in doing: social, cognitive, and computational perspectives. Situated learning: legitimate peripheral participation. Cambridge: Cambridge University Press.

Lu, M., Todd, A. and Miller, M. (2011) 'Creating a supportive culture for online teaching: a case study of a faculty learning community', Online Journal of Distance Learning Administration, 14(3), pp.84-93. https://doi.org/10.1080/14703297.2014.910129.

Knight, P. T. and Trowler, P. R. (2000) 'Department-level cultures and the improvement of learning and teaching', Studies in Higher Education, 25(1), pp.69-83. https://doi.org/10.1080/030750700116028.

Savage, K., Morrissey, S., Willison, D., Guccione, K. and Zike, J. (2021) Peer Support Networks: fostering a sense of belonging. Available at: https://strath.pagetiger.com/PSN/tools (Accessed: 3 June, 2021).

Vaughan, N. and Garrison, D. R. (2006) 'How blended learning can support a faculty development community of inquiry', Journal of Asynchronous Learning Networks, 10(4), pp.139-152.

\section{Author details}


Sean Morrissey (FHEA) is an Academic Developer at the University of Strathclyde. He leads the Learning and Teaching pathway within Strathclyde's credit-bearing PGCAP and PGCLTHE programmes. Sean's scholarship interests include digital empowerment for educators and students, assessment for learning in higher education, digital storytelling, and social media for impact. He is actively involved in research, consultancy, and knowledge exchange projects, and leads a programme of staff peer support networks at Strathclyde.

Katy Savage (SFHEA) is the Academic Director and Development Lead for Learning and Teaching at Strathclyde University. Her scholarship interests centre around the enhancement of learning and teaching within areas including student transitions in higher education, students as partners in Academic Development, innovative delivery methods (such as MOOCs and other blended/online pedagogies), use of Lego Serious Play in higher education, and leadership development in the higher education learning and teaching context, publishing her work and presenting at conferences where appropriate. 